Research Article

\title{
Screening of Selected Canola Cultivars for Yield and Tolerance against Mustard Aphid, Lipaphis erysimi Kalt. (Hemiptera: Aphididae)
}

\author{
Noor Muhammad* and Shah Alam Khan
}

Department of Plant Protection, Faculty of Crop Protection Sciences, The University of Agriculture, Peshawar; Pakistan.

Abstract | Canola (Brassica napus L.) is one of the economically important crops of Pakistan and mustard aphid, Lipaphis erysimi Kalt. (Hemiptera: Aphididae), is a serious threat to this crop. This experiment was conducted with an aim to screen out selected canola cultivars for their tolerance against $L$. erysimi infestation under glasshouse conditions. Experiment was carried out using completely randomized design with ten replications for each treatment during growing seasons of 2018 and 2019. Data were documented based on the tolerance indices (TI) and proportional plant dry weight change (DWT) to identify tolerance of canola crop. Results revealed that commercial cultivar 'Zahoor' comparatively performed well despite higher number of aphids found on itas compared its other counterparts "Abaseen, Omega and KS-75" and hence, was identified as tolerant to mustard aphid. This cultivar also exhibited strong vigor against mustard aphid and minimal symptoms of damages were observed. The yield losses based on DWT and TI in susceptible cultivar "Abaseen"was 40.79\%, whereas it was $23.56 \%$ in Zahoor which confirmed the reduced percent yield losses in the later genotype. This study identified "Zahoor" as the most tolerant cultivar to mustard aphid followed by KS-75 and Omega hence, other susceptible cultivars should be replaced by Zahoor to attain higher and sustainable yield production in canola.

Received | October 01, 2021; Accepted | February 05, 2022; Published | February 18, 2022

*Correspondence | Noor Muhammad, Department of Plant Protection, Faculty of Crop Protection Sciences, The University of Agriculture, Peshawar; Pakistan; Email: nmuhammad1084@aup.edu.pk

Citation | Muhammad, N. and S.A. Khan. 2022. Screening of selected canola cultivars for yield and tolerance against mustard aphid, Lipaphis erysimi Kalt. (Hemiptera: Aphididae). Sarhad Journal of Agriculture, 38(2): 497-503.

DOI | https://dx.doi.org/10.17582/journal.sja/2022/38.2.497.503

Keywords | Canola cultivar, Mustard aphid, Pest tolerance, Yield losses, Greenhouse

\section{Introduction}

$\mathrm{C}$ anola (Brassica napus (L.)) is among the most important rabbi (winter season) crops of Pakistan. However, its production is hampered by many diseases and insect pests' infestations. Insect pests and diseases are important factors responsible for the yield reduction in canola crop. Among insect pests, aphids are very destructive and serious threat to canola production in Pakistan (Aslam and Razaq, 2007; Tolba, 2020). Particularly, mustard aphid (Lipaphis erysimi) is a key pest that inflicts losses of around $96 \%$ in yield, $31 \%$ in seed weight and $5-6 \%$ in oil contents of can- ola crops (Dhaliwal et al., 2004; Rana, 2005; Shylesha et al., 2006). Moreover, yield losses of approximately $10 \%$ have been reported in certain mustard growing regions of Pakistan (Singh and Sachan, 1999).

Both adults and nymphs of $L$. erysimi may be congregate on leaves, flower, tender, stalks and pods that suck the cell sap and provide damage indirectly by secreting the honey-dew. Consequently, the affected plants loss their vitality, vigor and growth and becomes stunted and ultimately reduce the crop yield. Yield losses that occur only due to the mustard aphid (L. erysimi) in canola crop accounts for approximately 
50-75\%. Apart from sucking cell sap, it also acts as a vector of many viral diseases (Rana, 2005).

Several control strategies have been evolved so far to manage mustard aphids such as physically, mechanically, culturally, biologically, chemically and hosts plants resistant control. Particularly, aphid control on mustard and canola crops is primarily done using persistent synthetic insecticides. Injudicious use of chemical pesticides has led to many problems including the development of resistance in several species of insect pests, eradication of bio-control agents, environmental pollution and health hazards (Rana, 2005; Mpumi et al., 2020; Siviter et al., 2020). The development of insecticide resistance in various species of insect pests has forced the entomologists to opt for an alternative strategy. Thus, the most durable pest control is through integrated pest management strategy with no or little adverse effect on environment, economy, natural enemies and health hazard.

Plants that are resistant to herbivore insect pests have unique Physicomorphic and biochemical characters that enable them to resist insect attack. Many factors are involved in plant resistance to insect pests including antixenosis, antibiosis and tolerance (Acquaah, 2012). Due to consumer acceptance and market demand, the varietal resistance has received priority in IPM programmes. Cultivation of resistant or tolerant cultivars or plant cultivars is the very effective and cheapest method of cultural control to save the mustard crop from being attacked by insect pests. Utilization of resistant varieties or germplasms against aphids results in increased production and helps to reduce pesticides residues in the environment (Dey et al., 2005).

Keeping in view the importance of canola crop, selected cultivars of canola (B. napus) were further screened against aphid (L.erysimi) infestation and relative tolerance and yield parameters were determined under unsprayed conditions in a greenhouse. Results of this study would be helpful to local canola growers to find out aphid resistant/tolerant high yielding canola cultivars.

\section{Materials and Methods}

\section{Research area}

The study was conducted in a glasshouse at the Institute of Biotechnology and Genetic Engineering, The
University of Agriculture, Peshawar, Pakistan during the crop seasons of 2018 and 2019. Four selected cultivars viz. Abaseen, KS-75, Omega and Zahoor were used in the trials which were laid out in a complete randomized design with ten replications for each treatment.

\section{Preparation of plant and insect culture}

Plant culture was prepared to establish seedlings for aphid rearing. The seeds of our selected canola cultivars (B. napus) were individually sown in round mud trays. Aphid (L. erysimi) colonies were collected from the field and were carefully shifted on fresh plant (susceptible cultivars) for multiplication to further use in the experimentation in the glasshouse. Trays were filled with soils as a substrate. All trays were kept in the sliding metal trays to enable exchange of water and aeration. With great care plants in glasshouse were maintained at specific conditions $\left(20 \pm 2^{\circ} \mathrm{C}\right.$, $60-65 \% \mathrm{RH}$, and of $14: 10 \mathrm{~h}$ (D:L) photo-period). Plants cultures were observed for water levels and clean tap water was provided to the sliding metal trays if required, on daily basis. In case when plants get damaged, these were exchanged with new plants and aphids were also transferred to the new plants to maintain their colony for smooth running of the trial, while the old plants were carefully destroyed to avoid cross contamination. Pots were filled with potting mix materials. After emergence, plants were maintained in a growth chamber. Single seedling of each cultivar was planted in separate pots. Pot size was 16 $\mathrm{x} 32 \mathrm{~cm}$ height and circular length. Tolerance against the aphids was determined by caging an individual adult aphid on each cultivar at four to six leaves stage (seedling stage). Susceptible canola plants (for raising aphid colony), when required were substituted with a new plant and old plants were carefully destroyed to avoid cross contamination. When enough colonies of aphids started to establish, the L. erysimi were carefully introduced to fresh clean plants. Before transferring aphids to new plants, careful observations were made to check and identify the presence of mummified forms.

\section{Tolerance test}

For determining the presence of tolerant factors in the selected canola cultivars, procedure of Reese et al. (1994) was adopted. The proportionality plants dryweight changes (DWT) and tolerance indices (TI) were analyzed for each plant. The DWTs were recorded as DWTs $=[(\mathrm{WC}-\mathrm{WT}) / \mathrm{WC}] \times 100$, where 
WC is un-infested or control plants' dry-weight and WT is the dry-weight of infested or un-control plants. From DWTs, TI were recorded as TI= DWTs or number of aphids produced on infested plants. The plant cultivars having TI value significantly lower were considered tolerant in comparison to untreated cultivars (control). The pre-germinated seedlings of each cultivar were planted individually in pots $(6 \mathrm{~cm}-$ circular $\times 8.5 \mathrm{~cm}$ height) with 10 replications of each treatment. Within each cultivar, when plants were at four-six leaves stage, they were paired based on similarity of plants in heights and growths. In each pair, single plant was caged and left as un-treated (control), while other plant was infested with $25 \mathrm{~L}$. erysimi adult apterous individuals and plant was caged. The experiment was setup in a completely randomized design with one pair of the tested plants from each cultivar. Each pot was covered separately with organdy nylon mesh cages, and aphids were allowed to infest plants for 15 to 21 days till the susceptibility appeared or plants died. Cages were then removed and aphids on each infested plants were collected on a white paper sheet of wax, were put in $70 \%$ alcohol and were carefully counted. Shoots from the infested and un-infested plants were cut at soil surface and were put in pre-weighed aluminum foil pouches. Soil debris was carefully separated from the roots and was put again in the same pre-weighed aluminum foil pouches. Pouch with shoots/roots were dried in an oven at $75^{\circ} \mathrm{C}$ for about $48 \mathrm{~h}$. Tissue weight was determined by removing the weight of foil pouch from the combined weight of pouches and tissues. For yield data, colonies of L. erysimi were established on the plants of each cultivar in pots infested with a fixed number of 25 aphids per plant. Aphid population was recorded after 21 days post-infestation period to record aphid density and resultantly their impact on the yield.

The yield data were observed by harvesting the individual plants. Each cultivar was replicated ten times that were laid-out in completely randomized design. Percent yield losses were recorded from yield data in infested plots (treatment) and in un-infested plots (control) by the following formula;

$$
\mathrm{W}=\frac{(\mathrm{M}-\mathrm{Y})}{\mathrm{M}} \times 100
$$

\section{Where;}

W: Percent yield losses; M: Obtained yield in check (control) plants; Y: Yield in treatment(aphid infested plants).

\section{Statistical analysis}

The data were statistically analyzed using analysis of variance (STATISTIX Version 8.1 package) (Steel and Torrie, 1997). The F-value was calculated at the probability level $(p<0.05)$. The treatment means were further compared using least significant difference (LSD) post-hoc testat 5\% level of probability.

\section{Results and Discussion}

Results of proportional plant dry weight change (DWT) and tolerance index (TI) of all tested canola cultivars is shown in Table 1 . The statistical analysis for shoots of canola plants infested with mustard aphid (L. erysimi) revealed that all the tested cultivars showed significantly different response on the basis of DWT. The mean DWT values for shoots of KS75 cultivar (29.51\%) infested with L. erysimi was significantly less than that of Omega cultivar (31.79\%), followed by Zahoor cultivar (33.23\%), while maximum for the susceptible cultivar Abaseen (38.98\%). The average percent Tolerance index ratio of cultivar KS-75 (0.11\%) were recorded significantly lesser compared to cultivars Omega (0.15\%), Abaseen $(0.18 \%)$ and cultivar Zahoor $(0.18 \%)$, however, susceptible cultivar Abaseen and Zahoor were non significantly different to each other in terms of tolerance index.

Table 1: Percentage of proportional plant dry weight change (DWT) and tolerance index (TI) for shoot of canola plants (brasicca napus) infested with mustard aphid Lipaphis erysimi in 2018.

\begin{tabular}{lll} 
Cultivars & \multicolumn{2}{l}{ DWTand TI for shoots(\%) } \\
& Mean \pm SE DWT & Mean \pm SE TI \\
Abaseen & $38.98 \pm 0.03 \mathrm{~A}$ & $0.18 \pm 0.07 \mathrm{~A}$ \\
KS-75 & $29.51 \pm 0.02 \mathrm{D}$ & $0.11 \pm 0.02 \mathrm{C}$ \\
Omega & $31.79 \pm 0.03 \mathrm{C}$ & $0.15 \pm 0.05 \mathrm{~B}$ \\
Zahoor & $33.23 \pm 0.32 \mathrm{~B}$ & $0.18 \pm 0.06 \mathrm{AB}$ \\
LSD & 0.739 & 0.031
\end{tabular}

Means in each column with different letters are significantly different ( $p \leq 0.05 ; L S D)$.

The proportional plant dry weight change ratio (DWT) and tolerance Index (TI) parameters for roots of tested canola cultivars fed by L. erysimi are presented in Table 2, Response of all the cultivars involving roots fed by L. erysimi was significantly dif- 
ferent among the tested cultivars. Maximum (DWT) ratio was observed for Abaseen (46.21\%) plants compared to the other tested cultivars, while cultivar KS$75(18.25 \%)$ had shown significantly lower proportional plant dry weight changes (DWT) followed by Omega (33.39) and Zahoor (38.36\%). Similarly, the tolerance Index (TI) for plant roots fed by L. erysimi was also obtained significantly different among the tested cultivars. Maximum TI value was recorded for cultivar KS-75(0.11) followed by Omega (0.14\%), Zahoor (0.16\%) compared to susceptible Abaseen $(0.18 \%)$. The tolerance measurements for roots of plants infested by L. erysimi were similar to those of shoots for both DWT and TI values. The mean maximum TI value was recorded for cultivar (susceptible) Abaseen (0.18\%) followed by Zahoor $(0.16 \%)$ and Omega $(0.14 \%)$, while minimum was recorded on cultivar KS-75(0.11\%).

Table 2: Percentage of proportional plant dry weight change (DWT) and tolerance index (TI) for roots of canola plants (brasicca napus) infested with mustard aphid Lipaphis erysimi in 2018.

\begin{tabular}{lll} 
Cultivars & \multicolumn{3}{l}{ DWT and TI for roots(\%) } \\
& Mean \pm SE DWT & Mean \pm SE TI \\
Abaseen & $46.21 \pm 0.045 \mathrm{~A}$ & $0.18 \pm 0.002 \mathrm{~A}$ \\
KS-75 & $18.25 \pm 0.019 \mathrm{D}$ & $0.11 \pm 0.004 \mathrm{C}$ \\
Omega & $33.39 \pm 0.034 \mathrm{C}$ & $0.14 \pm 0.003 \mathrm{~B}$ \\
Zahoor & $38.36 \pm 0.039 \mathrm{~B}$ & $0.16 \pm 0.002 \mathrm{AB}$ \\
LSD & 0.125 & 0.036
\end{tabular}

Means in each column with different letters are significantly different ( $p \leq 0.05 ;$ LSD).

Data regarding relationship between L. erysimi density and yield losses in the tested canola cultivars are indicated in Table 3. The data indicated that aphid density recorded significantly higher on susceptible cultivar Abaseen (250.1 aphid plant ${ }^{-1}$ ) and low- er on cultivar KS-75 (65.40 aphid plant $\left.{ }^{-1}\right)$. Similarly, aphid density per plant was also recorded on cultivar Zahoor (245.8 aphid plant $^{-1}$ ), followed by cultivar Omega (200.3 aphid plant $\left.{ }^{-1}\right)$. All the tested cultivars responded against $L$. erysimi significantly different when compared with susceptible cultivar Abaseen. During the actual yield of untreated plants, maximum yield $(6.96 \mathrm{gm})$ was obtained in cultivar Zahoor and minimum in Abaseen plants $(4.67 \mathrm{gm})$, while culti$\operatorname{var} \mathrm{KS}-75(6.04 \mathrm{gm})$ and Omega falls in between the maximum and minimum; however, they were also significantly different from each other. Similarly, among the artificially aphid infested plants, cultivar Zahoor $(5.48 \mathrm{gm})$ yielded significantly higher followed by KS75 (3.28 gm), Omega (3.28 gm) and Abaseen (2.88 $\mathrm{gm})$ respectively. The last parameter of percent yield losses occurred due to aphid pressure recorded significantly higher in cultivar Abaseen (40.79\%) and lower in commercial cultivar Zahoor (23.56\%). While, yield losses of KS-75 (37.73\%) and Omega (38.03\%) obtained were non-significantly different from each other, but lower compared to susceptible Abaseen.

The response of the mechanism of host plant resistance towards insect behaviour has been explained by previous study by Kishor et al. (2019) who investigated that plants revealing antixenotic may produce volatiles induced pest repellence in plants. Furthermore, susceptible plants may also emit aversive odors and cause insect movement to cease in close proximity to the odor source (host). The inter play between the odors emitted by plant sources, the effects of the environment on these odors, the perception of the odors by insects and the resultant insect behaviors. The plant secondary metabolites either act as an insect repellent or serve as a host recognition using olfactory signals (Baldwin, 2010). Canola germplasms have been tested against aphid (L. erysimi) by various researchers

Table 3: Yield losses of canola (Brassica napus) cultivars incurred by mustard aphid Lipaphis erysimiin 2019.

\begin{tabular}{|c|c|c|c|c|}
\hline \multirow[t]{2}{*}{ Cultivars } & \multicolumn{4}{|l|}{ Percent yield losses } \\
\hline & Aphid density/ plant & Actual yield (gm) (control) & Infested plant yield (gm) & \%Yield loss(gm) \\
\hline Abaseen & $250.1 \pm 0.025 \mathrm{~A}$ & $4.67 \pm 0.038 \mathrm{D}$ & $2.88 \pm 0.017 \mathrm{C}$ & $40.79 \pm 0.003 \mathrm{~A}$ \\
\hline KS-75 & $65.40 \pm 0.065 \mathrm{D}$ & $6.04 \pm 0.039 \mathrm{~B}$ & $3.28 \pm 0.021 \mathrm{~B}$ & $37.73 \pm 0.004 \mathrm{~B}$ \\
\hline Omega & $200.3 \pm 0.020 \mathrm{C}$ & $4.98 \pm 0.038 \mathrm{C}$ & $3.28 \pm 0.021 \mathrm{~B}$ & $38.03 \pm 0.002 \mathrm{~B}$ \\
\hline Zahoor & $245.8 \pm 0.024 \mathrm{~B}$ & $6.96 \pm 0.040 \mathrm{~A}$ & $5.48 \pm 0.030 \mathrm{~A}$ & $23.56 \pm 0.002 \mathrm{C}$ \\
\hline LSD & 3.146 & 0.037 & 0.181 & 1.288 \\
\hline
\end{tabular}

Means in each column with different letters are significantly different ( $p \leq 0.05 ; L S D)$. 
(Matis et al., 2008; Sarwar, 2008; Rashid et al.,2009) regarding antixenosis test at different stages (vegetative, flowering and pod stage).

The analysis regarding Proportional Plant Dry Weight Change (DWT) and Tolerance Index (TI) analyzed for each cultivars, measurement involving shoots of canola plants infested against (L. erysimi), the mean DWT values for shoots of KS-75 plants infested with L. erysimi was significantly less than that of Omega, Zahoor and the susceptible cultivar Abaseen plants. Means (TI) values were also significantly different between shoot of the tested cultivars infested with L. erysimi. The tolerant measurement for roots of plants infested by L. erysimi was identical for the shoot of both (DWT) and (TI) value. The means DWT for roots of KS-75 plant infestation with $L$. erysimi was significantly less than mean roots DWT of Abaseen, Omega or Zahoor plants (Table 1 and 2). These results were also in similarity with that of Voothuluru et al. (2006) observing the importance of independent shoots and roots (DWT) measured rather than whole plants measurement. In this experiment, the tolerance expression in cultivar Zahoor may be due to activations of biomass accumulating metabolite genes as like in wheat crop, which are involved in cell repairing mechanism or photosynthesis regulations in response to RWA-1 (Smith et al., 2010) reported that several varieties of canola produced different quantities of biological yield with regard to shoot and roots organ of plants. Moreover, Murugan et al. (2010) calculated the DWT values for shoots, roots or both roots and shoots in infested as well as un-infested plants of barley with significant outcomes.

The percent yield losses analyses revealed that mustard aphids, L. erysimi after feeding and breeding on the resistant canola cultivar for twenty one days produced significantly lower numbers of aphids on cultivar KS-75 among the tested cultivars. This response of KS-75 proved characteristics of a resistant plant; however, the resistant category is judged by the yield correspondence (Smith and Boyd, 2005). When the actual yield within the control plants were compared to susceptible plants, maximum yield was obtained in commercial cultivar Zahoor (6.96 gm) and minimum was recorded in susceptible cultivar Abaseen $(4.67 \mathrm{gm})$.Similarly, the yield of artificially infested plants were compared among the tested cultivars where cultivar Zahoor $(5.48 \mathrm{gm})$ yielded significant- ly higher compared to other cultivars and minimum yield was obtained in Abaseen (2.88 gm). The higher yield obtained in cultivar Zahoor (both during un-infested and infested trials) speaks loudly for tolerance properties of thecommercial cultivar Zahoor. Furthermore, during percent yield losses caused by L. erysimi, maximum losses were recorded in cultivar Abaseen (40.97\%) and minimum percent yield losses were obtained in cultivar Zahoor (23.56\%) among the tested canola cultivars. These results are in line with Khan et al. (2015) where reported yield losses significantly higher in susceptible cultivar Crusher (43.83\%) and lower in resistant cultivar (11.08\%) in T-16-401 against Brevicoryne brassicae in Brassica cultivars. Furthermore, (Kumar and Sangha, 2013) also elaborated during their study that cultivar BSH 1 and YST 151 suffered high yield loss due to aphid infestation. On the other hand, resistant cultivars T-27 and DLSC2 sustained significantly lower aphid population and suffered the least yield loss and seedling mortality and can serve as important sources of resistance against mustard aphid during trials program of mustard/turnip aphid resistance. However, they could not categorize the resistant as antixenosis, antibiosis or tolerance. In contrast, in our current studies all the categories were evaluated separately based on all these three components and further the resistant category was calculated by the yield correspondence under treated and untreated plants.

\section{Conclusions and Recommendations}

It is concluded from the study results that susceptible cultivar 'Abaseen' suffered high yield loss due to aphid infestation compared to other tested cultivars, while the commercial cultivar Zahoor suffered the least. Thus, canola cultivar 'Zahoor' is proved tolerant cultivar against mustard aphid and is recommended to indigenous farmers in Pakistan in future breeding programmes. It can be used in future breeding programs against L. erysimi. As this type of pest tolerant cultivars may encourage natural enemies (predator, parasites and parasitoids) to keep the natural ecosystem balanced without compromising the crop yield.

\section{Acknowledgments}

The authors are highly grateful to the Higher Education Commission for providing all necessary facilities and funds for this research work. 


\section{Novelty Statement}

Canola (Brassica napus L.) is an important crop and mustard aphid, Lipaphis erysimi Kalt. (Hemiptera: Aphididae) is a serious threat to this crop. This study was conducted to screen out selected canola cultivars for their tolerance against $L$. erysimi infestation under glass-house conditions.

\section{Author's Contribution}

Noor Muhammad: PhD Scholar, who designed and conducted research. Did analysis and wrote this manuscript.

Shah Alam Khan: Major Supervisor, who provided technical guidelines and helped in analysis.

\section{References}

Acquaah, G. 2012. Principles of plant genetics and breeding. Blackwell Publishing Ltd, Oxford. www.blackwellpublishing.com

Aslam, M. and M. Razaq. 2007. Arthropod fauna of Brassica napus and Brassica juncea from Southern Punjab (Pakistan). J. Agric. Urban Entomol., 15(24): 49-50. https://doi. org/10.3954/1523-5475-24.2.49

Baldwin, I.T.2010. Plant volatiles seasonal dynamic of pests on mustard varieties (Brassica spp.) and relation to environmental factors. Curr. Biol., 20 (9): 392-397. https://doi.org/10.1016/j. cub.2010.02.052

Dey, M., C. Cao, A.C. Dar, T. Tamura, K. Ozato, F. Sicheri and T.E. Dever. 2005. Mechanistic Link between PKR Dimerization, Auto-phospho-rylation, and eIF2 Substrate Recognition. Cell. 122 (5): 901-913. https:// doi.org/10.1016/j.cell.2005.06.041

Dhaliwal, G.C., R. Arora, and A.K. Dhawan. 2004. Crop losses due to insect pest in Indian agriculture. Indian J. Ecol., 31(1): 1-7.

GoP. 2012-13. Economic Survey of Pakistan. Finance and Economic Affairs Division, Islamabad, Government of Pakistan. 21. Government of Pakistan Finance Division Islamabad www.finance.gov.pk.

Khan, I.A., M. Ahmad, R. Akbar, S. Hussain, M. Saeed, A. Farid, R.A. Shah, W. Fayaz, B. Shah and M.M. Din. 2015. A study on Losses due to Brevicoryne brassicae in different Brassica genotypes under screen house conditions. J. Ento-
mol.Zool. Stud., 3(6): 16-19. E-ISSN: 2320-7078 P-ISSN: 2349-6800 JEZS 2015.

Kishor, N.M, R. Singh, J. Singh, R. Nigam, W. Hasan and A. Kumar. 2019. Efficacy of novel insecticides against mustard aphid Lipaphis erysimi (Kalt.). Int. J. Agric. Inv., 3(1): $62-70.6800$ www.entomoljournal.com

Khan, S.A., M. Murugan, S. Starkey and C.M. Smith. 2009. Inheritance and categories of resistance in wheat to Russian wheat aphid (Hemiptera:Aphididae) biotype1 and biotype 2. J. Econ. Entomol., 102(9): 654-1662. https://doi. org/10.1603/029.102.0433

Kher, S. and H.S. Rataul. 1991. Investigation on the mechanism of resistance in oliferous Brassica against mustard aphid, Lipaphis erysimi (Kalt.). Indian J. Entomol., 7:141-154.

Kumar, S. and M.K. Sangha. 2013. Screening of wild crucifers for resistance to mustard aphid, L. erysimi (K.) and attempt at introgression of resistance gene(s) from B. fruticulosa to B. juncea. Springer Science, J. Euphytica., 179(5):461470. https://doi.org/10.1007/s10681-0110351-z

Matis, J.H., T.R. Kiffe, W. van der Werf, A.C. Costamagna, T.I. Matis and G.J. Michels. 2008. Comparisons of Two Symmetric Density Function Solutions of Aphid Population Growth Models. Appl. Stat. Agric., 1-17. https://doi. org/10.4148/2475-7772.1097

Mossler M.A. 2005. Florida Crop/Pest Management Profile: Specialty Brassicas (Arrugula, Bok Choy, Chinese Broccoli, Chinese mustard Napa) PI-70, Pesticide Information Office, University of Florida, USA. pp. 358. https:// ipmdata. ipmcenters. org/ documents/ cropprofiles /FLbrassicas2005.pdf.

Mpumi, N., R.S. Machunda, K.M. Mtei and P.A. Ndakidemi. 2020. Selected insects of economic importance to Brassica oleracea, their control strategies and the potential threat to environmental pollution in Africa. Sustainability, 12(9): 3824. https://doi.org/10.3390/su12093824

Murugan, M., S.A. Khan, P. Sotelo Cardona, G. Vargas Orozco, P. Viswanathan, J. Reese, S. Starkey and C.M. Smith. 2010. Variation of resistance in Barley against biotype 1 and 2 of the Russian Wheat Aphid (Hemiptra: Aphididae). J. Econ Entomol., 103(3): 938-948. https://doi. org/10.1603/EC09396

Rashid, M.H., M.M. Rahman, A.K.M.M. Rah- 
man, M. Mohiuddin and M.A.R. Choudhury. 2009. Study on the population dynamics of mustard aphid, L. erysimi (k) inrelation to weather parameters in Chittagong. J. Soil. Nature, 3(1): 20-22. http//www.gwf.org.bd/.8804473700-589.

Reese, J.C., J.R. Schwenke, P.S. Lamont and D.D. Zehr. 1994. Importance of quantification of plant tolerance in crop pest management programs for aphids: greenbug resistance in sorghum. J. Agric. Entomol., 11(8): 255-270.

Rana, J. 2005. Performance of Lipaphis erysimi (Homoptera: Aphididae) on different Brassica species in a tropical environment. Eur. J. Entomol., 103: 81-84. https://doi.org/10.1007/ s10340-005-0088-3

Sarwar, M.2008. Plant spacing-a nonpolluting tool for aphid (Hemiptera: Aphididae) management in canola. Brassica. J. Entomol. Soc. Iran, 27(2): $13-22$

Singh, C.P. and G.C. Sachan. 1999. Assessment of yield losses in yellow sarson due to mustard aphid, Lipaphis erysimi (Kalt.).J. Oil Res., 11(8): 179-84.

Siviter, H. and F. Muth. 2020. Do novel insecticides pose a threat to a beneficial insect? Proceed. Royal Soc., 287(1935): 20201265. https:// doi.org/10.1098/rspb.2020.1265

Shylesha, A.N, N. Thakur, N.S. Pathak, K.A. Rao, K.R. Saikia, K. Surose, S. Kodandaram and A. Kalaishekar. 2006 Integrated management of insect pests of crops in northeastern hill region. Technical Bulletin No. 19. ICAR RC for NEH Region, Umiam. pp. 50.

Smith, C.M. 2010. Plant resistance to arthropods: Molecular and conventional approaches. Springer, The Netherlands Springer. pp. 423.

Steel, R.G.D. and Torrie, J.H. 1997. Principles and procedures of statistics. McGraw Hill Book Co., Inc., New York, pp. 232-251.

Tolba, E.F.M. 2020. Population fluctuation of the green peach aphid, Myzuz persicae (SULZ.) (Homoptera: Aphididae) infesting canola plants at Assiut area. J. Plant Prot. Path., 11(1): 15-18. https://doi.org/10.21608/jppp.2020.79159

Vootuluru, P., Meng, J., Khauria, C., Louis, J., Zhu, Starkey, S., Wilde, G.E., Baker, CA. and Smith, C.M. 2006. Categories and inheritance of resistance to Russian wheat aphid (Hemiptera: Aphididae) biotype 2 in a selection from wheat cereal introduction 2401. J. Econ. Entomol., 99(5): 1854-1861. https://doi.org/10.1093/ jee/99.5.1854 